\title{
Research on the Measurement of Carbon Storage in Plantation Tree Trunks Based on the Carbon Storage Dynamic Analysis Method
}

\author{
Weida Yin, ${ }^{1}$ Mingfang Yin, ${ }^{2}$ Lin Zhao, ${ }^{2}$ and Lin Yang ${ }^{2}$ \\ ${ }^{1}$ Graduate School of Frontier Science, The University of Tokyo, Tokyo, Japan \\ ${ }^{2}$ College of Forestry, Shenyang Agriculture University, Shenyang, China
}

Correspondence should be addressed to Mingfang Yin, yinssss@163.com

Received 29 February 2012; Accepted 13 May 2012

Academic Editor: Qing-Lai Dang

Copyright (C) 2012 Weida Yin et al. This is an open access article distributed under the Creative Commons Attribution License, which permits unrestricted use, distribution, and reproduction in any medium, provided the original work is properly cited.

\begin{abstract}
Estimation of forest carbon storage can be of great significance to the research on the productivity of terrestrial ecosystem, carbon cycle, and global warming. China has more than 54 million $\mathrm{hm}^{2}$ barren hills and waste land suitable for forestation, which provides a great potential for developing carbon sink forestry by means of forestation. This research analyzed the volume increments, volume densities, and carbon contents of 15 analytical samples of five main plantation tree species in North China, including Pinus tabulaeformis (A), Robinia pseudoacacia (B), Populus euramericana (C), Larix olgenisis (D), and Larix kaempferi (E). Results showed that carbon storage dynamic process can be expressed as follows: the ages of quantitative maturity of each tree species are $67 \mathrm{a}, 40 \mathrm{a}, 30 \mathrm{a}, 48 \mathrm{a}, 49 \mathrm{a}$, respectively; the average wood densities of each tree species at different age classes are $550.93 \mathrm{~kg} / \mathrm{m}^{3}$, $629.25 \mathrm{~kg} / \mathrm{m}^{3}, 404.56 \mathrm{~kg} / \mathrm{m}^{3}, 592.33 \mathrm{~kg} / \mathrm{m}^{3}$, and $544.11 \mathrm{~kg} / \mathrm{m}^{3}$,t. The average carbon contents of each tree species at different age classes are $51.48 \%, 46.88 \%, 47.81 \%, 46.76 \%$, and $47.24 \%$. It showed a significant difference between the above tree species through variance test. The maximum values of average carbon storage are 70a, 40a, 30a, 48.7a, and 49.2a, respectively. The corresponding average carbon storages are A $2.527 \mathrm{~kg}, \mathrm{~B} 3,794 \mathrm{~kg}, \mathrm{C} 2.781 \mathrm{~kg}, \mathrm{D} 2.996 \mathrm{~kg}$, and E 3,322 kg, in a descending order of C > E > D > $\mathrm{B}>\mathrm{A}$. This research, through experiment on four tree species with clear growth rings and one tree species with unclear growth rings, verified the scientific character and the scope of application of the carbon storage dynamic analysis method, providing a new method for the measurement and analysis of forest carbon storage.
\end{abstract}

\section{Introduction}

Large-scale devastation of natural vegetation including forests and grasslands has impaired the carbon sequestration capacity of the biosphere. Moreover the release of inactive carbon from consumption and burning of fossil fuels (coal and petroleum) has led to a considerable increase of $\mathrm{CO}_{2}$ in the atmosphere [1-5]. To prevent the global warming, it is legally imperative to cut down the emission of greenhouse gases [6]. The international community is making various efforts to control the emission of greenhouse gases. As forests maintain over $86 \%$ of the terrestrial carbon stock on earth, an accurate estimate of forest carbon storage will be of great significance to the research on the productivity of terrestrial ecosystem, carbon cycle, and global warming, and so forth.
Researches on the forest carbon storage and carbon flux have attracted extensive attentions [6].

Over the past 20 years, plenty of researches focusing on the carbon storage, carbon density, and carbon sink function of forest ecosystem have been made by many countries $[7,8]$. Using the volume-derived method, a number of scholars have estimated the changes in carbon storage of global, national, and regional forest vegetation on a timescale basis [9-11]. Also, China's scholars have estimated and calculated the carbon storage in forest vegetation planted in some of China's provinces or regions [12-16]. Although the means and methods for the research are being improved and innovated, their differences in method, time, and space scale make it difficult to apply the research findings and prediction more widely or internationally $[17,18]$. 
As a country with scarce forest resources, China has more than 54 million $\mathrm{hm}^{2}$ barren hills and waste land suitable for forestation, which provides a great potential for developing carbon sink forestry by means of forestation. Since 2004, the State Forestry Administration has launched pilot projects of forestry carbon sinks in 6 provinces (autonomous regions) including Inner Mongolia. The rapid development of carbon sink forestry presses for a method for carbon storage measurement, and in the matter of plantation and operation of carbon sink forests, measurement and evaluation methods that can reflect the change of forest carbon storage are required so as to scientifically determine the tree species and operating cycle for carbon sink forestation.

\section{Study Area}

In this research, we selected 5 primary forestation tree species planted in Liaoning: Pinus tabulaeformis, Larix olgenisis, Larix kaempferi, Robinia pseudoacacia, and Populus euramericana. Pinus tabulaeformis and Robinia pseudoacacia samples were taken from Wendao Forest Farm of Fushun County $\left(41^{\circ} 45^{\prime} \sim 41^{\circ} 53^{\prime} \mathrm{N}, 124^{\circ} 1^{\prime} \sim 124^{\circ} 8^{\prime} \mathrm{E}\right)$. This region features its temperate continental monsoon climate with a mean annual precipitation of $800 \sim 900 \mathrm{~mm}$, a maximum temperature of $35.8^{\circ} \mathrm{C}$, a minimum temperature of $-34^{\circ} \mathrm{C}$, a mean temperature of $7.8^{\circ} \mathrm{C}$, and a frost-free period of 130 $140 \mathrm{~d}$. The forest land is characterized by its brown forest soil with a soil thickness of $30 \sim 55 \mathrm{~cm}$ and a humus horizon of $10 \mathrm{~cm}$. It is a low mountainous region with an altitude of $200 \sim 300 \mathrm{~m}$ and a gradient of $15 \sim 25^{\circ}$. The most common tree species in this region are Larix olgenisis, Larix kaempferi, Pinus tabulaeformis, Pinus koraiensis, Pinus sylvestnis, Robinia pseudoacacia, and other man-made forests. In the natural forests are mainly planted with Quercus liaotungensis [19]. The Populus euramericana samples were taken from Xinmin Mechanical Forest Farm $\left(41^{\circ} 48^{\prime} \sim 42^{\circ} 16^{\prime} \mathrm{N}, 122^{\circ} 26^{\prime} \sim\right.$ $122^{\circ} 45^{\prime} \mathrm{E}$ ), which is located west of Liaohe River and belongs to the sand-drift region north of Liaohe River Plain with an average altitude of $29 \mathrm{~m}$. This region is low lying and flat, featured by its temperate continental monsoon climate with a mean annual temperature of $7.8^{\circ} \mathrm{C}$, an extreme high temperature of $36.5^{\circ} \mathrm{C}$, an extreme low temperature of $-31.5^{\circ} \mathrm{C}$, a mean annual precipitation of $605.7 \mathrm{~mm}$, and a forest-free period of 150-160 d. The underground water level is $1 \sim 4 \mathrm{~m}$ deep, and most of the soil here is carbonate meadow soil formed on the alluvium parent materials out of river inundations. The main tree species here include Populus euramericana, Populus simonii, Populus pseudo-simonii, Salix matsudana and Ulmus pumila [19]. The Larix olgenisis and Larix kaempferi samples were taken from Dabiangou Forest Farm $\left(41^{\circ} 59 \sim 42^{\circ} 04^{\prime} \mathrm{N}, 124^{\circ} 59 \sim 125^{\circ} 10^{\prime} \mathrm{E}\right)$ of Qingyuan Manchu Autonomous County. Belonging to Longgang branch range of Changbai Mountain with an average altitude of $500 \sim 600 \mathrm{~m}$, this region is situated at a mid-low mountain land, featured by its continental monsoon climate, cold and dry in winter, hot and rainy in summer, with a mean annual temperature of $5^{\circ} \mathrm{C}$, a minimum temperature of $-37.7^{\circ} \mathrm{C}$, a frost-free period of $120 \sim 125 \mathrm{~d}$, and an annual rainfall of $700 \sim 800 \mathrm{~mm}$. The forest soil here is mostly brown forest soil. Man-made forests are mainly planted with such conifers as Larix kaempferi, Larix olgenisis, Pinus koraiensis and Pinus tabulaeformis, and in the natural secondary forests are Fraxinus mandshurica, Fraxinus rhynchophylla, Quercus mongolica, and Quercus Liaotungensis [20].

\section{Methods}

3.1. Theory. The carbon storage dynamic analysis is a method to explore the change in carbon storage speed of forest trees at different age classes during growth. This method bases on the close correlation between growing stock (stem volume) and tree biomass [12] and the widely verified Theoretical Volume Equation with high accuracy and fitness that is of universal significance to the measurement of the stem volume of conifers [21]. Since the annual carbon storage in forests is a variable attached to the tree volume growth percentage [22], thus we can just devote ourselves to the measurement of carbon storage in stem biomass in place of the measurement of stem volume increment and subdivide carbon storage into such indexes as volume increment, wood density, and carbon content. This method aims to explore the carbon storage in forest trees and its change law at different stages (each age gradation) [20] through subdividing the carbon storage process into such indexes as the volume increment, wood density and carbon content of forest trees at different stages, measuring directly with instruments, and then a chain of calculations and analyses of these data. For man-made forests that feature their straight trunks and less branches, we can measure and evaluate the result of carbon storage in trunks of different tree species during growth in a direct-viewing and handy way and further calculate the tree biomass by use of such a characteristic as high positive correlation between growing stock and tree biomass, calculate the tree biomass based on the law of change in carbon storage on the time series, and ultimately realize the measurement and evaluation of carbon storage in forest trees.

3.2. Experimental Design and Measuring Method. Plots with the highest stand age and moderate conditions for tree growth were selected from five of main tree species planting areas as the standard woodlands, including one Pinus tabulaeformis and Robinia pseudoacacia sample plot at Wendao Forest Farm of Fushun County, one Populus euramericana sample plot at Xinmin Mechanical Forest Farm, one Larix olgenisis sample plot and one Larix kaempferi sample plot at Dabiangou Forest Farm of Qingyuan Manchu Autonomous county, each having a size of $20 \mathrm{~m} \times 30 \mathrm{~m}$. The experiment was carried out by selecting as samples Robinia pseudoacacia, Pinus tabulaeformis, Larix olgenisis, and Larix kaempferi that have clear growth rings and Populus euramevicana that has unclear growth rings, in order to verify the feasibility of this experimental method when it is used for the tree species with different growth ring structures. The stand ages of Pinus tabulaeformis, Robinia pseudoacacia, Populus euramevicana, Larix olgenisis, and Larix kaempferi were 85a, 45a, 28a, $45 \mathrm{a}$, and $45 \mathrm{a}$ respectively; their average diameters at breast height were $24.6 \mathrm{~cm}, 26.5 \mathrm{~cm}, 24.8 \mathrm{~cm}, 23.4 \mathrm{~cm}$, and $25.8 \mathrm{~cm}$ 
respectively; their average heights were $18.3 \mathrm{~m}, 20.4 \mathrm{~m}$, $24.8 \mathrm{~m}, 25.2 \mathrm{~m}$, and $26.1 \mathrm{~m}$ respectively; their stand densities were $672 \mathrm{~N} / \mathrm{hm}^{2}, 716 \mathrm{~N} / \mathrm{hm}^{2}, 640 \mathrm{~N} / \mathrm{hm}^{2}, 655 \mathrm{~N} / \mathrm{hm}^{2}$, and $623 \mathrm{~N} / \mathrm{hm}^{2}$, respectively. Single tree measurement was made in each sample plot to calculate the average diameter at breast height, and three standard trees were selected according to their average diameter at breast height, from each sample plot for a stem analysis. Belt transects were taken from each disc to measure the wood density, and block samples were taken on an age gradation basis from each belt transect to measure the carbon content. All the data obtained through measurements and analyses were the average values of the three analytic tree samples, as shown in Table 1.

3.2.1. Growth Increment Measurement. The stem analysis method, a method to explore the growth process of forest trees, was adopted to measure the growth increment. Cut each trunk into sections, and on each cross section measure the diameter increments at every age gradation based on the growth ring widths, and on the profile calculate the tree height increment at different ages based on the crosssection height and the difference of growth rings between adjacent profiles, thus the volumes and form factors [23] can be calculated. Cut down the sample trees at a height of ground diameter, and cut the trunks into $2 \sim 4 \mathrm{~cm}$ thick discs at intervals of $0 \mathrm{~m}, 1 \mathrm{~m}, 1.3 \mathrm{~m}, 3 \mathrm{~m}, 5 \mathrm{~m}$, and so forth for a diameter measurement. The age gradation of Pinus tabulaeformis, Robinia pseudoacacia, Larix olgenisis and Larix kaempferi was 5a, and that of Populus euramevicana was 2a. Use LINTAB5 Growth ring Measuring Apparatus to measure the growth increment of each disc at different age classes along eastwest and northsouth diameter lines (to the accuracy of $0.01 \mathrm{~mm}$ ), take their average value as the age gradation diameter value, then calculate the current annual increment and periodic average increment of stem volume at different age classes, to express the growth speed of forest trees at a certain moment (one year) and their average growth speed at a certain stage (stand age).

3.2.2. Wood Density Measurement. Wood density means the mass of wood per unit volume. Wood density is related with growth ring width, and the latter is related directly with carbon storage, so the wood ring density plays an important role in analyzing the change of carbon storage [24]. In general, there are four types of wood density [25] according to the difference of water content in wood, and the basic density of wood (hereinafter called wood density) was adopted in this paper. Across the pith, cut the discs into $1 \mathrm{~cm}$ wide and high belt transects one by one in the south-north direction, and then cut the belt transects into block samples on an age gradation length basis, which should be sealed with market-sold plastic membrane and marked with numbers for later use. Put all the block samples into DHG-9053A electrothermal blowing dry box $\left(103 \pm 2^{\circ} \mathrm{C}\right)$ for drying. Select $2 \sim 3$ clock samples for a trial weighing for the first time, carry out the second trail weighing in 2 hours, and repeat the experiment several times. At last, carry out the third trial weighing. When the difference of measured value between the third and the second weighing is within an order of magnitude of $10^{-3}$, the samples will be judged to be fully dry:

$$
\rho_{y}=\frac{m_{0}}{V},
$$

where $\rho_{y}$ is the basic density of wood, $\mathrm{kg} \cdot \mathrm{m}^{-3} ; m_{0}$ is the mass of fully dried wood, $\mathrm{kg} ; V$ is the volume of green wood.

3.2.3. Carbon Content Measurement. Sample from the numbered block samples with different age classes, of which Pinus tabulaeformis and Populus euramevicana were sampled mechanically from every two age classes, but for other tree species, from every age gradation. Put the carbon content samples into FZ102 mini plant disintegrator for crushing (to a diameter of 100 meshes), and take $10 \mathrm{mg}$ of the crushed samples to pack up and mark with number, and at last, put the samples into a Vario ELIII elemental analyzer (made by Germany's Elementar Company) to measure the carbon contents. Burn the samples at $1150^{\circ} \mathrm{C}$ in a combustion chamber by the dynamic combustion method, with the help of an oxygen-adding device so that the samples could oxidize and decompose in the flow of high-concentration oxygen and helium. Since the samples were crushed as fine as 100 meshes and only a little amount was taken, the samples could be burnt completely. The combustion product was reduced to $\mathrm{N}_{2}$ and $\mathrm{SO}_{2}$ in a reduction tube that was provided with a copper wire and heated up to $850^{\circ} \mathrm{C} . \mathrm{SO}_{2}$ and $\mathrm{H}_{2} \mathrm{O}$ in the mixed gas were removed one by one, and $\mathrm{CO}_{2}$ was absorbed when passing through a U-shape tube. Heat the U-shaped tube to release $\mathrm{CO}_{2}$, which simultaneously was detected by TCD, thus $\mathrm{C}$ content could be calculated [26].

3.3. Data Calculation. The data sorting and analysis were realized under Excel 2003 through variance analysis and multiple comparison and calculation by use of SPSS17 software. Corresponding wood density, carbon content and volume increment were used to calculate the carbon storage at different stages. Such two indexes as current annual carbon storage and average carbon storage were adopted to calculate and analyze the carbon storage dynamic change $[12,21]$, calculated through the following equations:

$$
\begin{aligned}
& C_{\theta}=C_{c} \times \rho_{y} \times \theta_{A}, \\
& C_{z}=C_{c} \times \rho_{y} \times Z_{A},
\end{aligned}
$$

where $C_{\theta}$ is the current annual carbon storage, $\mathrm{kg} ; C_{z}$ is the average carbon storage, $\mathrm{kg} ; C_{c}$ is the carbon content, $\% ; \rho_{y}$ is the wood density, $\mathrm{kg} \cdot \mathrm{m}^{-3} ; \theta_{A}$ is the current annual increment of volume, $\mathrm{m}^{3} ; Z_{A}$ : average increment of volume, $\mathrm{m}^{3}$.

\section{Results}

4.1. Analyses of the Growth Process of Stem Volume. The diameter data of each age classes was input into the analysis software called Forstat 2.0 Wood of Statistics. By using of the stem analysis function of the statistic software, the average increments and current annual increments of volume of all the experimental tree species were calculated, as shown in Table 2. 
TABLE 1: Diameters at breast height and heights of sample trees.

\begin{tabular}{|c|c|c|c|c|c|c|c|}
\hline \multirow{2}{*}{ Sample tree } & \multirow{2}{*}{ Age } & \multirow{2}{*}{ Tree species } & \multicolumn{2}{|c|}{ Diameter at breast height $(\mathrm{cm})$} & \multirow{2}{*}{ Tree height $(\mathrm{m})$} & \multirow{2}{*}{ Slope locality } & \multirow{2}{*}{ Slope orientation } \\
\hline & & & With bark & Without bark & & & \\
\hline 1 & & & 23.2 & 22.3 & 18.9 & Center & South \\
\hline 2 & 85 & Pinus tabulaeformis & 25.5 & 24.4 & 18.5 & Center & South \\
\hline 3 & & & 23.4 & 22.2 & 18.0 & Center & South \\
\hline 4 & & & 26.2 & 23.9 & 20.6 & Center & Southwest \\
\hline 5 & 45 & Robinia pseudoacacia & 26.8 & 24.4 & 20.8 & Center & Southwest \\
\hline 6 & & & 26.3 & 24.5 & 20.2 & Center & Southwest \\
\hline 7 & & & 25.3 & 24.2 & 24.5 & Center & Flat \\
\hline 8 & 28 & Populus euramericana & 24.9 & 23.3 & 25.0 & Center & Flat \\
\hline 9 & & & 23.1 & 22.0 & 24.0 & Center & Flat \\
\hline 10 & & & 24.5 & 22.9 & 27.8 & Down & South \\
\hline 11 & 45 & Larix olgensis & 23.6 & 22.0 & 24.9 & Center & South \\
\hline 12 & & & 22.0 & 21.6 & 23.0 & Center & South \\
\hline 13 & & & 26.2 & 24.9 & 26.2 & Center & Northwest \\
\hline 14 & 45 & Larix kaempferi & 25.9 & 23.8 & 24.0 & Center & Northwest \\
\hline 15 & & & 25.4 & 23.1 & 28.0 & Upper & Northwest \\
\hline
\end{tabular}

The current annual increment of Pinus tabulaeformis keeps increasing in a uniform speed basically before $40 \mathrm{a}$, but speeds up after 40a and reaches the peak at 55 60a, then drops down gradually. The average increment of Pinus tabulaeformis increases slowly before $25 \mathrm{a}$, but speeds up gradually after that, and tends to be steady with the increase in age. The curves of the current annual increment and the average increment intersect at $65 \mathrm{a}$. The current annual increment of Robinia pseudoacacia begins increasing rapidly from 10a, slows down gradually from 25a, and begins dropping down year by year since reaching the peak at $35 \mathrm{a}$. Its average increment keeps increasing in a uniform speed after $10 \mathrm{a}$ and reaches the peak at $45 \mathrm{a}$. The curves of the current annual increment and the average increment intersect at 40a. The current annual increment of Populus euramevicana increases rapidly before $10 \mathrm{a}$, then begins slowing down after that until 20a when its growth speeds up, reaches the peak at $24 \mathrm{a}$, and drops down gradually after that. Its average increment increases rapidly before $10 \mathrm{a}$, and slows down after 10a until 20a when its average increment continues to increase. No intersect between the current annual increment and the average increment is found yet, but it is estimated through the tendency chart that they will intersect at 30a. The current annual increment of Larix olgensis increases slowly before 10a, begins speeding up after 10a, drops down a little at 30a, reaches the peak at $35 \mathrm{a}$, and slows down gradually at $35 \mathrm{a}$. Its average increment increases slowly before 10a and increases significantly after 10a until 45a. No intersect between the current annual increment and the average increment is found yet, but it is estimated through the tendency chart that they will intersect at 49a. The current annual increment of Larix kaempferi increases slowly before $10 \mathrm{a}$, speeds up gradually after that until $25 \mathrm{a}$ when an inflection point appears, as is just like Larix olgenisis, and reaches the peak at 25a. Its average increment increases rapidly before $20 \mathrm{a}$ and tends to be steady after $30 \mathrm{a}$. It can be estimated that the curves of the current annual increment and average increment of this tree species tend to intersect.

4.2. Analysis of Wood Density of Trunks at Different Stages. Measurement and calculation of wood density were performed using of formula (1). The wood density of the five tree species varies regularly with the increase in age (Table 2). The wood density of Pinus tabulaeformis and Robinia pseudoacacia tends to increase slowly all the way since they begin growing until $35 \mathrm{a}$ when reaching the peak. After 35a, the wood density of Pinus tabulaeformis drops down slowly, but that of Robinia pseudoacacia drops down rapidly; that of Populus euramevicana increases in a quick speed before $4 \mathrm{a}$, but slowly at $4 \mathrm{a} \sim 18 \mathrm{a}$ and reaches the peak at 18a, and tends to drop down after 18a till 28a; that of Larix olgenisis and Larix kaempferi tend to increase since they begin growing, reach the peak at $30 \mathrm{a}$, and drop down gradually and tend to be steady after 30a. This demonstrates that the wood density of the same tree species fluctuates greatly at different growth stages.

The average values (standard deviation) of wood density of the above tree species are as follows: Robinia pseudoacacia $629.25 \mathrm{~kg} / \mathrm{m}^{3}$ (43.86), Larix olgenisis $592.33 \mathrm{~kg} / \mathrm{m}^{3}$ (73.41), Pinus tabulaeformis $550.93 \mathrm{~kg} / \mathrm{m}^{3}$ (42.70), Larix kaempferi $544.11 \mathrm{~kg} / \mathrm{m}^{3}$ (56.23), and Populus euramevicana $404.56 \mathrm{~kg} / \mathrm{m}^{3}$ (14.84), showing an extremely remarkable difference between the five tree species $(P=0.000<$ $0.01)$ through variance test. Through multiple comparison by LSD method, the difference is extremely remarkable $(P=0.000<0.01)$ between Pinus tabulaeformis, Robinia 
TABLE 2: Four carbon contents of five tree species.

\begin{tabular}{|c|c|c|c|c|c|c|}
\hline \multirow{2}{*}{ Age } & \multicolumn{2}{|c|}{ Volume growth process $\left(\mathrm{m}^{3}\right)$} & \multicolumn{2}{|c|}{ Carbon storage $\left(\mathrm{m}^{3}\right)$} & \multirow{2}{*}{$\begin{array}{l}\text { Wood density } \\
\text { unit: } \\
\mathrm{kg} \cdot \mathrm{m}^{-3}\end{array}$} & \multirow{2}{*}{$\begin{array}{c}\text { Carbon } \\
\text { percent } \%\end{array}$} \\
\hline & $\begin{array}{l}\text { Current annual } \\
\text { increment }\end{array}$ & $\begin{array}{c}\text { Average } \\
\text { increment }\end{array}$ & $\begin{array}{c}\text { Average carbon } \\
\text { storage }\end{array}$ & $\begin{array}{c}\text { Annual carbon } \\
\text { storage }\end{array}$ & & \\
\hline \multicolumn{7}{|c|}{ Pinus tabulaeformis } \\
\hline $0-5$ & & 0.0001 & & & 497.77 & \\
\hline $5-10$ & 0.0011 & 0.0004 & 0.1295 & 0.3237 & 507.01 & 59.30 \\
\hline $10-15$ & 0.0016 & 0.0006 & & & 526.77 & \\
\hline $15-20$ & 0.0026 & 0.0010 & 0.3123 & 0.8582 & 537.36 & 60.52 \\
\hline $20-25$ & 0.0032 & 0.0014 & & & 540.23 & \\
\hline $25-30$ & 0.0038 & 0.0017 & 0.5260 & 1.1564 & 565.69 & 54.44 \\
\hline $30-35$ & 0.0050 & 0.0029 & & & 630.43 & \\
\hline $35-40$ & 0.0057 & 0.0043 & 1.2388 & 1.6390 & 617.92 & 46.34 \\
\hline $40-45$ & 0.0074 & 0.0054 & & & 606.13 & \\
\hline $45-50$ & 0.0089 & 0.0065 & 1.8378 & 2.5149 & 593.61 & 47.39 \\
\hline $50-55$ & 0.0113 & 0.0079 & & & 575.90 & \\
\hline $55-60$ & 0.0119 & 0.0089 & 2.2816 & 3.0596 & 557.36 & 46.14 \\
\hline $60-65$ & 0.0104 & 0.0094 & & & 536.14 & \\
\hline $65-70$ & 0.0087 & 0.0100 & 2.5266 & 2.1952 & 542.63 & 46.64 \\
\hline $70-75$ & 0.0077 & 0.0104 & & & 531.58 & \\
\hline $75-80$ & 0.0067 & 0.0104 & 2.2764 & 1.7890 & 522.66 & 51.04 \\
\hline $80-85$ & 0.0059 & 0.0107 & 1.8340 & 1.3500 & 476.64 & \\
\hline \multicolumn{7}{|c|}{ Robinia pseudoacacia } \\
\hline $0-5$ & & 0.0001 & & & 591.03 & 56.96 \\
\hline $5-10$ & 0.0008 & 0.0005 & 0.1416 & 0.2511 & 622.37 & 49.06 \\
\hline $10-15$ & 0.0042 & 0.0017 & 0.5337 & 1.3138 & 629.24 & 49.18 \\
\hline $15-20$ & 0.0087 & 0.0050 & 1.8557 & 3.2187 & 657.07 & 46.52 \\
\hline $20-25$ & 0.0133 & 0.0065 & 1.8101 & 3.6722 & 649.72 & 42.58 \\
\hline $25-30$ & 0.0143 & 0.0102 & 2.9793 & 4.1840 & 663.76 & 44.16 \\
\hline $30-35$ & 0.0157 & 0.0128 & 3.6607 & 4.8712 & 693.49 & 44.79 \\
\hline $35-40$ & 0.0135 & 0.0139 & 3.7939 & 3.6752 & 611.31 & 44.69 \\
\hline $40-45$ & 0.0108 & 0.0144 & 3.4503 & 2.5868 & 545.28 & 43.98 \\
\hline \multicolumn{7}{|c|}{ Larix olgensis } \\
\hline $0-5$ & & 0.0003 & & & 472.00 & 48.76 \\
\hline $5-10$ & 0.0031 & 0.0017 & 0.3959 & 0.7311 & 501.00 & 46.76 \\
\hline $10-15$ & 0.0084 & 0.0039 & 1.0175 & 2.1752 & 562.00 & 46.18 \\
\hline $15-20$ & 0.0107 & 0.0056 & 1.5712 & 2.9890 & 605.00 & 46.32 \\
\hline $20-25$ & 0.0135 & 0.0074 & 2.1369 & 4.1977 & 622.00 & 46.50 \\
\hline $25-30$ & 0.0125 & 0.0083 & 2.6508 & 4.0076 & 700.00 & 46.01 \\
\hline $30-35$ & 0.0137 & 0.0091 & 2.8034 & 4.2621 & 672.00 & 46.29 \\
\hline $35-40$ & 0.0134 & 0.0096 & 2.7348 & 3.8553 & 611.00 & 46.76 \\
\hline $40-45$ & 0.0117 & 0.0104 & 2.8827 & 3.2475 & 586.00 & 47.25 \\
\hline \multicolumn{7}{|c|}{ Larix kaempferi } \\
\hline $0-5$ & & 0.0004 & & & 438.00 & 48.00 \\
\hline $5-10$ & 0.0045 & 0.0024 & 0.5589 & 1.0186 & 488.00 & 47.87 \\
\hline $10-15$ & 0.0097 & 0.0048 & 1.1568 & 2.3207 & 512.00 & 46.92 \\
\hline $15-20$ & 0.0142 & 0.0072 & 1.8326 & 3.6304 & 543.00 & 47.17 \\
\hline
\end{tabular}


Table 2: Continued.

\begin{tabular}{|c|c|c|c|c|c|c|}
\hline \multirow{2}{*}{ Age } & \multicolumn{2}{|c|}{ Volume growth process $\left(\mathrm{m}^{3}\right)$} & \multicolumn{2}{|c|}{ Carbon storage $\left(\mathrm{m}^{3}\right)$} & \multirow{2}{*}{$\begin{array}{c}\text { Wood density } \\
\text { unit: } \\
\mathrm{kg} \cdot \mathrm{m}^{-3}\end{array}$} & \multirow{2}{*}{$\begin{array}{c}\text { Carbon } \\
\text { percent } \%\end{array}$} \\
\hline & $\begin{array}{l}\text { Current annual } \\
\text { increment }\end{array}$ & $\begin{array}{c}\text { Average } \\
\text { increment }\end{array}$ & $\begin{array}{c}\text { Average carbon } \\
\text { storage }\end{array}$ & $\begin{array}{c}\text { Annual carbon } \\
\text { storage }\end{array}$ & & \\
\hline $20-25$ & 0.0168 & 0.0091 & 2.4271 & 4.4944 & 570.00 & 46.84 \\
\hline $25-30$ & 0.0166 & 0.0103 & 3.0188 & 4.8385 & 624.00 & 46.80 \\
\hline $30-35$ & 0.0177 & 0.0112 & 3.0803 & 4.8592 & 583.00 & 46.99 \\
\hline $35-40$ & 0.0166 & 0.0118 & 3.1637 & 4.4547 & 568.00 & 47.26 \\
\hline $40-45$ & 0.0140 & 0.0128 & 3.4507 & 3.8254 & 571.00 & 47.33 \\
\hline \multicolumn{7}{|c|}{ Populus euramericana } \\
\hline $0-2$ & & 0.0001 & 0.0822 & 0.1551 & 384.14 & \\
\hline $2-4$ & 0.0008 & 0.0004 & & & 407.91 & 47.92 \\
\hline $4-6$ & 0.0043 & 0.0017 & 0.8200 & 2.2632 & 408.91 & \\
\hline $6-8$ & 0.0113 & 0.0041 & & & 412.19 & 48.47 \\
\hline $8-10$ & 0.0137 & 0.0069 & 1.6176 & 2.8315 & 415.81 & \\
\hline $10-12$ & 0.0140 & 0.0080 & & & 416.36 & 48.62 \\
\hline $12-14$ & 0.0144 & 0.0089 & 1.9176 & 3.0212 & 418.82 & \\
\hline $14-16$ & 0.0148 & 0.0094 & & & 418.95 & 48.64 \\
\hline $16-18$ & 0.0154 & 0.0098 & 2.0625 & 3.3437 & 419.05 & \\
\hline $18-20$ & 0.0171 & 0.0105 & & & 413.73 & 47.38 \\
\hline $20-22$ & 0.0244 & 0.0118 & 2.5357 & 5.3738 & 394.99 & \\
\hline $22-24$ & 0.0293 & 0.0138 & & & 391.04 & 46.98 \\
\hline $24-26$ & 0.0290 & 0.0150 & 2.8130 & 4.0303 & 382.17 & \\
\hline $26-28$ & 0.0228 & 0.0159 & 2.5266 & 2.1952 & 379.79 & 46.64 \\
\hline $24-26$ & 0.0077 & 0.0104 & & & 531.58 & \\
\hline $26-28$ & 0.0067 & 0.0104 & 2.2764 & 1.7890 & 522.66 & 51.04 \\
\hline $80-85$ & 0.0059 & 0.0107 & 1.8340 & 1.3500 & 476.64 & \\
\hline
\end{tabular}

pseudoacacia, and Populus euramevicana, between Robinia pseudoacacia, Larix kaempferi, and Populus euramevicana, and between Populus euramevicana, Larix olgenisis, and Larix kaempferi; the difference is remarkable between Larix olgenisis, Pinus tabulaeformis $(P=0.010<0.05)$, and Larix kaempferi $(P=0.033<0.05)$. The wood density analysis results demonstrate that wood densities between different tree species are great.

4.3. Analysis of Carbon Content in Trunks at Different Stages. Carbon contents of these five tree species at different age classes were measured as shown in Table 4. According to the table, Pinus tabulaeformis has higher carbon content at $10 \mathrm{a}$ and $20 \mathrm{a}$, and reaches the peak at $20 \mathrm{a}$ up to $60.52 \%$, minimum $46.14 \%$ at $40 \mathrm{a}$. In general, the carbon content of Pinus tabulaeformis fluctuates greatly during its whole growth process, but tends to be steady after $40 \mathrm{a}$; the carbon content of Robinia pseudoacacia is high at $5 \mathrm{a} \sim 20 \mathrm{a}$, reaches the peak at $5 \mathrm{a}$, up to $56.96 \%$, and drops down rapidly after $25 \mathrm{a}$, minimum $42.58 \%$ at $25 \mathrm{a}$, having a great fluctuation during the whole growth process, but tends to be steady after 25a; changing slightly during its whole growth process, the carbon content of Populus euramevicana increases slowly at $4 \mathrm{a} \sim 16 \mathrm{a}$ and reaches the peak at $16 \mathrm{a}$, up to $48.64 \%$, minimum $46.64 \%$ at $28 \mathrm{a}$; the maximum carbon content of Larix olgenisis is $48.76 \%$, the minimum is $48.00 \%$, having a great fluctuation. Its carbon content is very high at $5 \mathrm{a} \sim 10 \mathrm{a}$, then drops down gradually, to the minimum at $30 \mathrm{a}$, but increases again gradually with the increase in age, then keeps steady basically with the growth of forest trees; the maximum carbon content of Larix kaempferi is $48.00 \%$, the minimum $46.80 \%$, having a slight fluctuation. Its carbon content is high at $5 \mathrm{a}$, slows down after that, and drops down to the minimum at 30a, then increases slowly after 30a. Larix olgenisis and Larix kaempferi have a more consistent carbon content than the other tree species.

On the basis of analysis, the average carbon contents of Pinus tabulaeformis, Robinia pseudoacacia, Larix olgenisis, Larix kaempferi, and Populus euramevicana were worked out to be $51.48 \%(5.94 \%), 46.88 \%(4.41 \%), 46.76 \%(0.84 \%)$, $47.24 \%(0.43 \%)$, and $47.81 \%(0.82 \%)$, respectively. Through variance test, the carbon contents between different tree species are remarkably different $(P=0.037<0.05)$. The result of multiple comparisons by LSD method is that 
there is an extremely remarkable difference between Pinus tabulaeformis, Robinia pseudoacacia and Larix olgenisis; there is a remarkable difference between Pinus tabulaeformis, Larix kaempferi, and Populus euramevicana. The carbon content research results demonstrate that there is a great difference in the carbon content of the five tree species, and the carbon content fluctuates at different growth stages. The research also demonstrates that carbon storage dynamic analysis method can be used to measure the true carbon content of different tree species and the same tree species at different growth stages in a more accurate way.

4.4. Calculation of Carbon Storage in Trunks at Different Stages. The carbon storage was worked out through analyzing the increment, density, and carbon content of stem volume; therefore, the differences in increment, wood density and carbon content of different tree species would surely lead to the difference in carbon storage. The carbon storage can be divided into current annual carbon storage and average carbon storage (Figure 1). The current annual carbon storage and average carbon storage of Pinus tabulaeformis, Robinia pseudoacacia and Populus euramevicana show a change trend basically alike at different age classes_increasing with age and slowing down when reaching the peak. The current annual carbon storage of Pinus tabulaeformis reaches the peak at $60 \mathrm{a}$, and its average carbon storage reaches the peak at 70a; the current annual carbon storage of Robinia pseudoacacia reaches the peak at 35a, and its average carbon storage reaches the peak at $40 \mathrm{a}$; the current annual carbon storage of Populus euramevicana reaches the peak at $24 \mathrm{a}$, but no maximum of its average carbon storage appears yet. The current carbon storage and average carbon storage of Larix olgenisis intersect at 48.7a; the current carbon storage and average carbon storage of Larix kaempferi intersect at 49.2a.

According to the forest maturity theory, the carbon storage maturity age refers to the time when the average carbon storage of a tree reaches the peak [19, 22]. Based on the method to determine the maturity age, we worked out the carbon storage maturity ages of the previous tree species as follows (average carbon storage): Pinus tabulaeformis 70a (2.5267 kg); Robinia pseudoacacia 40a (3.7939 kg); Populus euramevicana 30a $(2.7810 \mathrm{~kg})$; Larix olgenisis $48.7 \mathrm{a}$ $(2.996 \mathrm{~kg})$; Larix kaempferi $49.2 \mathrm{a}(3.322 \mathrm{~kg})$, in a descending order of Robinia pseudoacacia > Larix kaempferi $>$ Larix olgenisis) > Populus euramevicana $>$ Pinus tabulaeformis.

In order to forecast and evaluate the average carbon storage of the above tree species at different growth stages, a regression analysis was made for the calculation results of their carbon storage, by use of the following regression formula:

Pinus tabulaeformis:

$$
\begin{aligned}
y_{1}= & 0.635-0.078 a+0.003 a^{2} \\
& -2.724 \times 10-5 a^{3} \quad\left(R^{2}=0.996\right) ;
\end{aligned}
$$

Robinia pseudoacacia:

$$
y_{2}=0.416-0.139 a+0.013 a^{2} \quad\left(R^{2}=0.978\right)
$$

Populus euramevicana:

$$
y_{3}=-0.636+0.209 a-0.003 a^{2} \quad\left(R^{2}=0.982\right) ;
$$

Larix olgenisis:

$y_{4}=-0.9348+0.8398 a-0.0466 a^{2} \quad\left(R^{2}=0.981\right) ;$

Larix kaempferi:

$y_{5}=-1.0089+0.933 a-0.0505 a^{2} \quad\left(R^{2}=0.981\right) ;$

where " $y_{i}$ " represents the carbon contents of the above tree species, and " $a$ " represents the stand age.

\section{Conclusion and Discussion}

Scientific verification of the carbon storage dynamic analysis method: the carbon storage dynamic analysis method realizes the scientific measurement on the long-time storage of carbon in stem volume of the same tree species. The dynamic data about carbon storage during the whole growth process obtained through this method can evaluate the true change in carbon storage in a more accurate way than the carbon content coefficient method that is commonly used. This method provides a theoretical basis for how to select plantation tree species for small-scale sites and how to determine the operation cycle. Favorable verifications were obtained through experiment on four types of broadleaf trees and conifers with clear growth rings and a type of broadleaf tree with unclear growth rings; simultaneously, the scope of application of this method was verified, that is, this method is applied to not only the tree species with clear growth rings, but those with unclear growth rings.

Analyses of the volume increment of different tree species: the increments of the five tree species are greatly different on account of such factors as tree species characteristics and site conditions, and so forth, but change regularly in the form of quadratic or cubic equation curve at different growth stages. The mature ages of Pinus tabulaeformis, Robinia pseudoacacia, Robinia pseudoacacia, Larix olgenisis, and Larix kaempferi obtained from this experiment are 67a, 40a, 30a, 48a, and 49a, respectively, consistent with most research results achieved before. This demonstrates that the selected experimental plots are typical ones, which make the subsequent wood density and carbon content analysis results more reliable.

Analyses of wood density of the above tree species: there is a remarkable difference between the above five tree species in wood density, which shows a change tendency similar to a conic. Pinus tabulaeformis shows a tendency to increase slowly at its initial growth stage, reaches the peak at 35a, drops down gradually after that, and tends to be steady; the wood density of Robinia pseudoacacia increases slowly before $30 \mathrm{a}$, but drops down in a quick speed after 30a; the wood density of Populus euramevicana increases in a quick speed before $4 \mathrm{a}$, but slowly at $4 \mathrm{a} \sim 18 \mathrm{a}$, and tends to decrease after 18a; the wood density of Larix olgenisis and Larix kaempferi, which belong to the same tree species, changes in a very similar way, but the former is far higher than the later. 


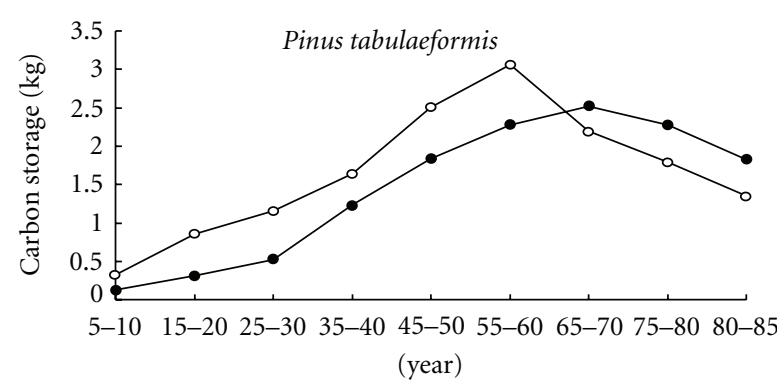

(a)

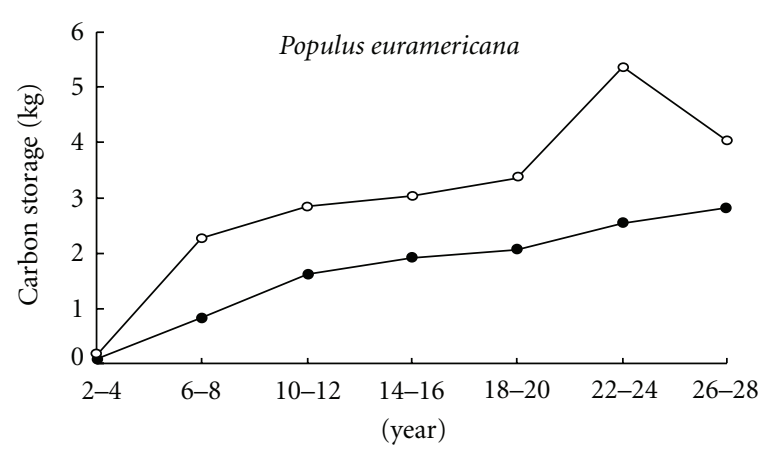

(c)

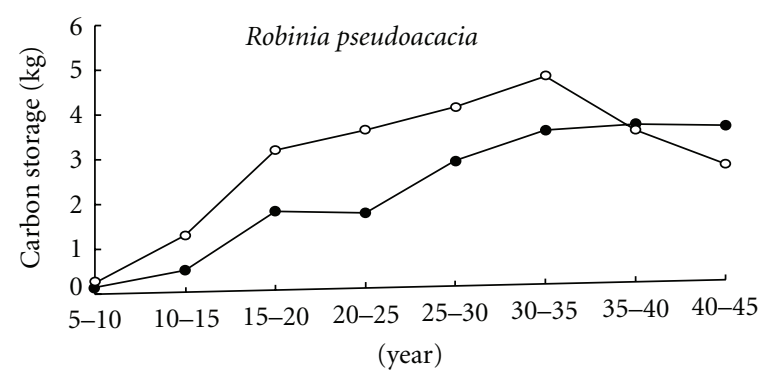

(b)

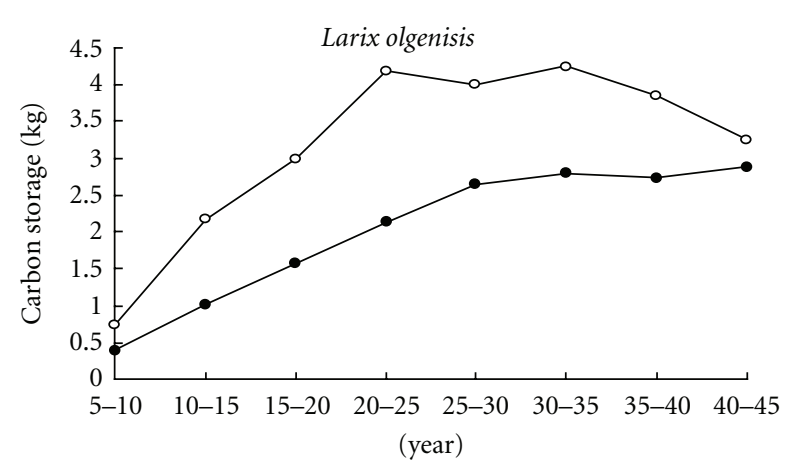

(d)

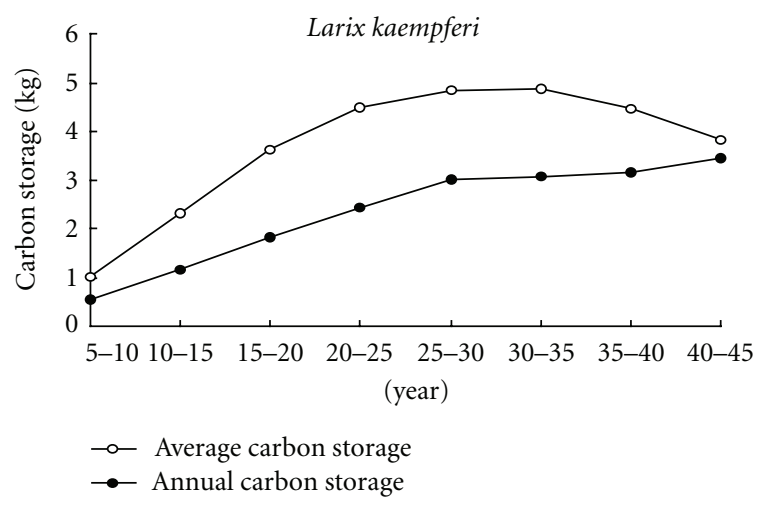

(e)

FIGURE 1: The growth curve of annual carbon storage and average carbon storage of five tree species.

Analyses of carbon content of the above tree species: among the above five experimental tree species, Pinus tabulaeformis has the highest carbon content, over 50\%, but for the other tree species, lower than 50\%. According to the variance analysis results, the difference in carbon content of Pinus tabulaeformis, Robinia pseudoacacia, and Larix olgenisis at different stages is extremely remarkable; for Populus euramevicana and Larix kaempferi, the difference is remarkable. The carbon contents of these tree species are similar to precious researches [27]. The dynamic analysis results demonstrate that the carbon content of Pinus tabulaeformis reaches $60.52 \%$ at $15 \mathrm{a} \sim 20 \mathrm{a}$, drops down to the minimum $46.14 \%$ at $40 \mathrm{a}$, with a severe fluctuation, but tends to be steady after 40a; the carbon content maximum of Robinia pseudoacacia appears at $20 \mathrm{a}$, up to $56.96 \%$, drops down to the minimum $42.58 \%$ at $25 \mathrm{a}$, with a severe fluctuation, but tends to be steady after 25a; the carbon content of Populus euramevicana increases slowly all the way before $16 \mathrm{a}$, but drops down slowly after 16a, with a maximum of $48.64 \%$ and minimum of $46.64 \%$; the change in carbon contents of Larix olgenisis and Larix kaempferi is steady and similar, but Larix kaempferi has a higher carbon content than Larix olgenisi, though the difference is not remarkable. This is just opposite to the wood density of the above tree species.

Carbon storage maturity of the above tree species: carbon storage maturity is a term put forward by reference to the forest quantitative maturity theory. According to the quantitative maturity theory, the average carbon storage reaches the peak when the curves of current annual carbon storage and average carbon storage intersect, that is, the carbon storage maturity age is reached, so felling trees at such a time can realize an optimal utilization of land [19, 24, 28]. 
This research demonstrates that the average carbon storages of Pinus tabulaeformis, Robinia pseudoacacia, Populus euramevicana, Larix olgenisis, and Larix kaempferi are $2.527 \mathrm{~kg}, 3.794 \mathrm{~kg}, 2.781 \mathrm{~kg}, 2.996 \mathrm{~kg}$, and $3.322 \mathrm{~kg}$, appearing at their 70a, 40a, 30a, 48.7a, and 49.2a, respectively, in a descending order of Robinia pseudoacacia $>$ Larix kaempferi $>$ Larix olgenisis $>$ Populus euramevicana $>$ Pinus tabulaeformis. The carbon storage regression formulas for the above tree species obtained from this paper may also be applied to the prediction and evaluation of carbon storage.

Knowledge on the carbon storage in trunks that was obtained through this research: first, the carbon storage of the above tree species calculated by this method relies on the comprehensive effect of such three factors as carbon content, wood basic density, and the average increment of volume. This experiment demonstrates that some tree species, for example, Pinus tabulaeformis, have lower carbon content, though their carbon content is very high. Also, the maximum values of average carbon storage of different tree species appear at different age classes, which should be given full consideration in the process of forestation and operation, especially in the carbon sink function management of the existing forests; in addition, though the carbon contents of the five tree species are similar to those of constructive species of main forest types in North China [27], which demonstrates that there is a slight difference in the carbon content for the same tree species at different regions, however, whether there is regional difference in carbon storage for the same tree species? What is the effect of various operation means and site conditions on the carbon storage of each tree species? There is lack of researches yet on these aspects nowadays, for which we must make more efforts.

\section{Acknowledgment}

This study was funded by the National Natural Science Fund Projects of China, no. 30972364.

\section{References}

[1] R. Bacastow and C. D. Keeling, "Atmospheric carbon dioxide and radio carbon in the natural carbon cycle: changes from A.D.1700 to 2070 as deduced from a geochemical model," in Brookhaven Symposium in Biology, Carbon and the Biosphere, G. M. Woodwell and E. V. Pecan, Eds., Atomic Energy Commission, Washington, DC, USA, 1973.

[2] D. M. Etheridge, L. P. Steele, R. J. Francey, and R. L. Langenfelds, "Atmospheric methane between 1000 A.D. and present: evidence of anthropogenic emissions and climatic variability," Journal of Geophysical Research D, vol. 103, no. 13, pp. 1597915993, 1998.

[3] C. D. Keeling and T. P. Whorf, Atmospheric $\mathrm{CO}_{2}$ Records from Sites in the SIO Air Sampling Network // Trends: A Compendium of Data on Global Change, Carbon Dioxide Information Analysis Center, Oak Ridge National Laboratory, U. S. Department of Energy, Oak Ridge, Tenn, USA, 2002.

[4] J. S. Olson, J. A. Watts, and L. J. Allison, "Carbon in Live vegetation of Major World Ecosystems," Report ORNL 258620, Oak Ridge National Laboratory, Oak Ridge, Tenn, USA, 1983.
[5] L. Augustin, C. Barbante, P. R. F. Barnes et al., "Eight glacial cycles from an Antarctic ice core," Nature, vol. 429, no. 6992, pp. 623-628, 2004.

[6] M. R. Davis, R. B. Allen, and P. W. Clinton, "Carbon storage along a stand development sequence in a New Zealand Nothofagus forest," Forest Ecology and Management, vol. 177, no. 1-3, pp. 313-321, 2003.

[7] J. Y. Fang, "Forest productivity in China and its response to global climate change," Acta Phytoecologica Sinica, vol. 24, no. 5, pp. 513-517, 2000.

[8] G. H. Liu, B. J. Fu, and J. Y. Fang, "Carbon dynamics of Chinese forests and its contribution to global carbon balance," Acta Ecologica Sinica, vol. 20, no. 5, pp. 733-740, 2000.

[9] R. K. Dixon, S. Brown, R. A. Houghton, A. M. Solomon, M. C. Trexler, and J. Wisniewski, "Carbon pools and flux of global forest ecosystems," Science, vol. 263, no. 5144, pp. 185-190, 1994.

[10] R. A. Birdsey, A. J. Plantinga, and L. S. Heath, "Past and prospective carbon storage in United States forests," Forest Ecology and Management, vol. 58, no. 1-2, pp. 33-40, 1993.

[11] D. F. Grigal and L. F. Ohmann, "Carbon storage in upland forests of the Lake States," Soil Science Society of America Journal, vol. 56, no. 3, pp. 935-943, 1992.

[12] J. Y. Fang, A. P. Chen, and S. Q. Zhao, "Estimating biomass carbon of china s forests: supplementary notes on report published in science by Fang et al," Acta Phytoecologica Sinica, vol. 26, no. 2, pp. 243-249, 2002.

[13] K. R. Li, S. Q. Wang, and M. K. Cao, "Carbon storage in China's vegetation and soils," Science in China D, vol. 33, no. 1, pp. 72-80, 2003.

[14] D. Q. Zhang, W. G. Sang, R. F. Li et al., "Forest organic carbon storage and its trend in Shandong province," Acta Phytoecologica Sinica, vol. 26, pp. 93-97, 2002.

[15] J. Cao, Y. L. Zhang, and Y. H. Liu, "Changes in forest biomass carbon storage in Hainan Island over the last 20 years," Geographical Research, vol. 21, no. 5, pp. 551-560, 2002.

[16] D. S. Guan, Y. J. Chen, and F. F. Huang, "The storage and distribution of carbon in urban vegetation and its roles in balance of carbon and oxygen in Guangzhou," China Environmental Science, vol. 18, no. 5, pp. 437-441, 1998.

[17] D. Schimel, J. Melillo, H. Tian et al., "Contribution of increasing $\mathrm{CO} 2$ and climate to carbon storage by ecosystems in the United States," Science, vol. 287, no. 5460, pp. 2004-2006, 2000.

[18] J. A. Dunne, S. R. Saleska, M. L. Fischer, and J. Harte, "Integrating experimental and gradient methods in ecological climate change research," Ecology, vol. 85, no. 4, pp. 904-916, 2004.

[19] M. F. Yin, L. Yang, and W. D. Yin, "Dynamic changes of carbon storage in trunk volume of Pinus tabulaeformis, Robinia pseudoacacia and Populus euramericana," Journal of Beijing Forestry University, vol. 33, no. 5, pp. 65-68, 2011.

[20] M. F. Yin, L. Zhao, X. F. Chen, S. Cao, and C. S. Hou, "Carbon storage maturity age of Larix olgenisis and L. kaempferi," Chinese Journal of Applied Ecology, vol. 19, no. 12, pp. 25672571, 2008.

[21] Inoue, "Application of theoretical volume equation to Japanese cedar," Applied Forest Science, vol. 15, no. 1, pp. 3336, 2006.

[22] K. J. Lang, C. S. Li, and Y. Yin, "The measurement theory and method of 10 forest ecological benefits for forestry ecological engineering," Journal Of Northeast Forestry University, vol. 28, no. 1, pp. 1-7, 2000. 
[23] X. Y. Meng, Forest Measurement, China Forestry Press, Beijing, China, 1998.

[24] K. Zhang, Researches on Estimation Method of Forest Carbon Sequestration, Beijing Forestry University, Beijing, China, 2007.

[25] Q. Y. Ma, J. F. Ma, F. F. Kang et al., "Functions of water conduction in sapwood and heartwood of Pinus tabulaeformis in Taiyue Mountain of Shanxi Province, north China," Journal of Beijing Forestry University, vol. 27, no. 2, pp. 156-159, 2005.

[26] D. E. Dong and T. H. Li, "Measurement of carbon sulfur element in the coal by the Vario," EL Element Analyzer, no. 4, pp. 36-38, 2004.

[27] Q. Y. Ma, X. L. Chen, and J. Wang, "Carbon content rate in constructive species of main forest types in northern China," Journal of Beijing Forestry University, vol. 9, no. 24, pp. 5-6, 2002.

[28] D. L. Shi, "Study on carbon storage maturity of Pinus massoniana forest," Forest Resources Management, no. 4, pp. 34-37, 2007. 

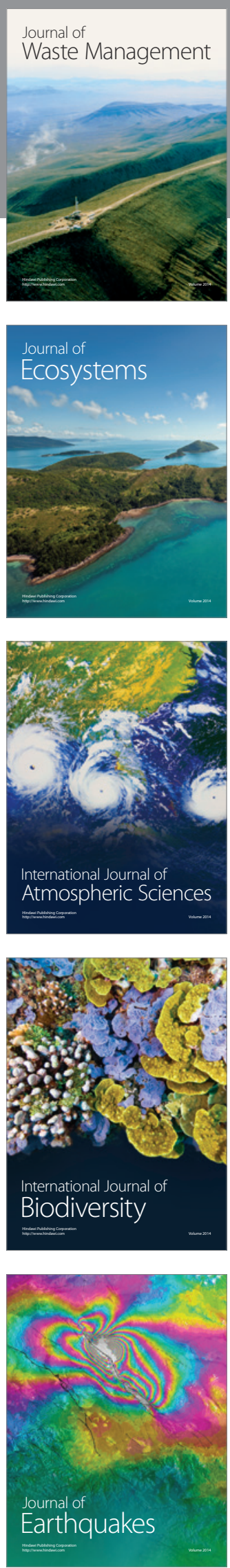
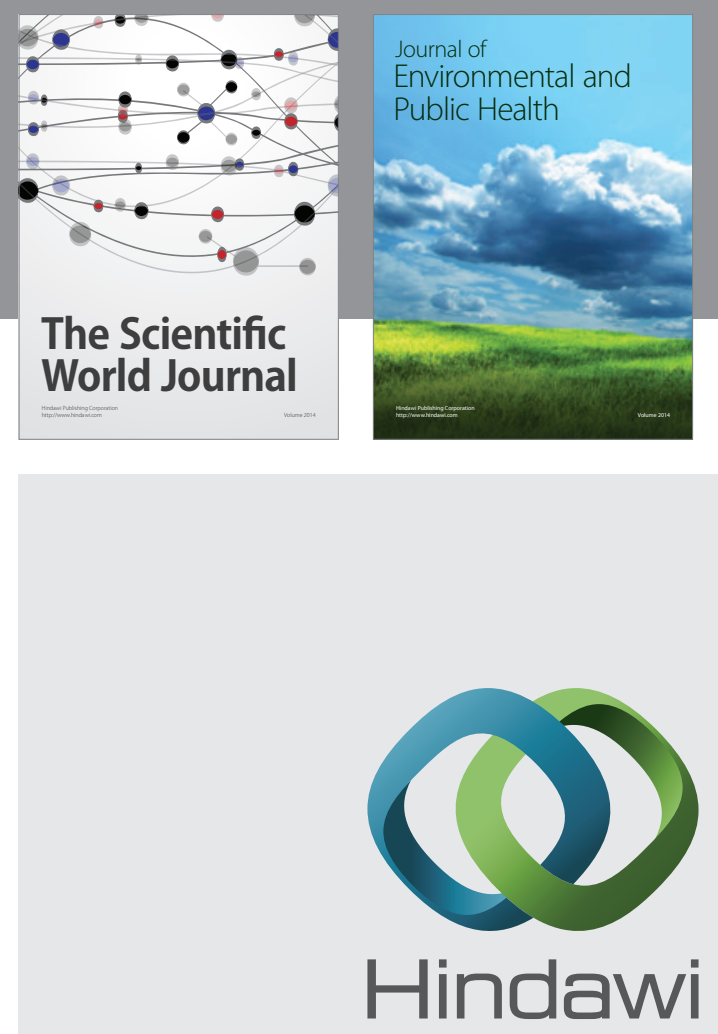

Submit your manuscripts at

http://www.hindawi.com
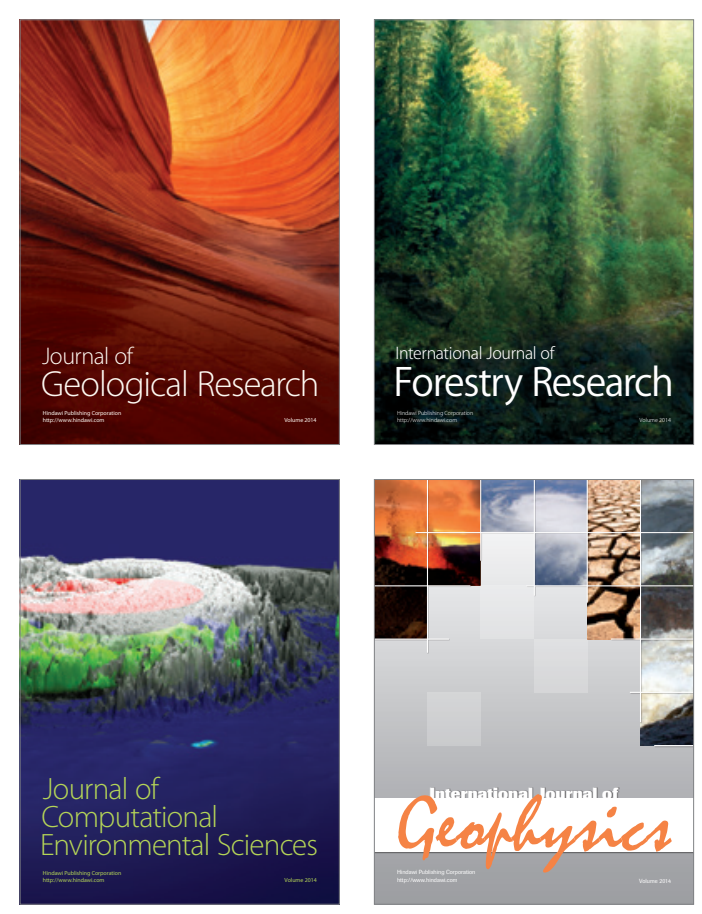
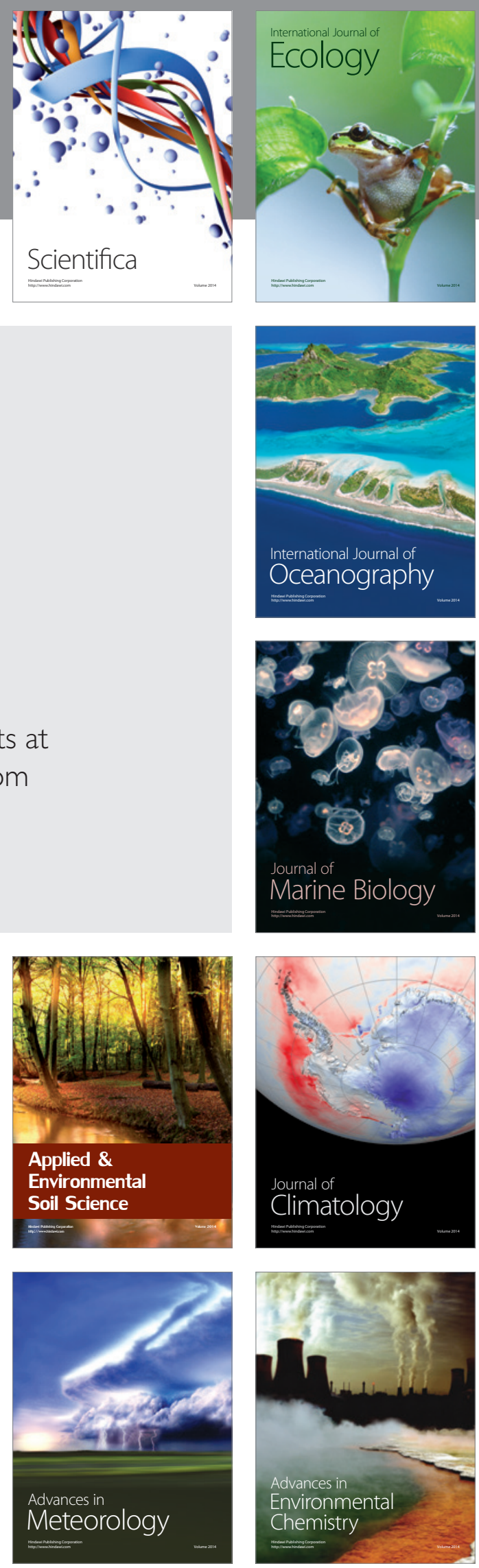